\title{
Os desafios profissionais do historiador
}

\author{
Flavia Renata Machado Paiani*
}

Banner Jr., James M. Being a Historian. An Introduction to the Professional World of History. Nova York: Cambridge University Press, 2012.

Ser historiador significa, certamente, algo mais que estudar o passado e pesquisar em bibliotecas e arquivos. No livro Being a Historian: an Introduction to the Professional World of History, o historiador estadunidense James M. Banner Jr. preocupa-se em mostrar que os historiadores não devem estar circunscritos à carreira acadêmica (preocupação que se explicita, sobretudo, no terceiro e no quinto capítulos). Embora ele analise a realidade profissional do historiador nos Estados Unidos, suas indagaçôes também são pertinentes à realidade brasileira na medida em que compartilhamos muitas das inquietaçôes sobre o futuro de nosso ofício.

Em um primeiro momento, o autor busca diferenciar a disciplina "história" da profissão que se debruça sobre ela. Para ele, a profissão diz respeito à "direção e à maneira com que é utilizado um cabedal de conhecimento, e não ao cabedal de conhecimento em si” (p. 4). Ele destaca que a profissão requer uma educaçáo mais ou menos uniforme no conjunto de conhecimento e protocolos de prática de pesquisa - ou seja, é a formação acadêmica que diferenciará o "historiador profissional" do "historiador amador". Nesse sentido, o autor assinala que os historiadores profissionais não ficam restritos a uma única profissão, podendo atuar como acadêmicos, editores, consultores, escritores independentes, curadores em museus etc.

O leitor brasileiro talvez estranhe algumas profissóes sugeridas por Banner Jr., pois, em linhas gerais, o historiador no Brasil segue majoritariamente a docência - seja na educação básica, seja na educação superior. Ainda nos é recente a luta em torno do projeto de lei (PL) sobre a regulamentação de nossa profissão para que possamos repensar nossos espaços de atuação. Ademais, ainda nos é pouco conhecida a noção de "história pública" - discutida entre os historiadores estadunidenses desde a década de 1970 - que nos permite, do mesmo modo, ampliar nosso leque de atuação e nosso papel na sociedade.

Assim, dividido em oito capítulos, o cerne do livro não é pautado apenas no debate sobre história acadêmica e história pública: seu foco é a redefinição do lugar (profissional e, em certa medida, social) ocupado pelo historiador. Todavia, essa redefiniçáo perpassa os rumos tomados pela disciplina de história, bem como o monopólio que a 
universidade tende a exercer sobre ela. Ainda assim, o autor ressalta que as mudanças mais significativas pelas quais a disciplina passou nos últimos anos desenvolveram-se precisamente fora do meio acadêmico. Ele destaca, em especial, o papel da American Historical Association (AHA) — "hoje em dia, a maior e mais antiga organização de historiadores profissionais nos Estados Unidos e, indiscutivelmente, a organização histórica mais importante do mundo" — que pode ser igualada a um departamento acadêmico no que concerne à sua influência sobre o modo como a história é ensinada e praticada nos Estados Unidos (p. 42). No caso brasileiro, caberia nos questionarmos o papel historicamente desempenhado pela Associação Nacional de História, cuja sigla — ANPUH — originalmente remete não a uma associação de historiadores, mas a uma associação de professores universitários de história. A ampliação do número de associados, bem como sua relativa heterogeneidade (não são mais os professores universitários exclusivamente), desemboca também na pressão pela regulamentação da profissão de historiador, de que trata o PL 4.699/2012.

Em realidade, o ideal acadêmico impregna a disciplina desde o século XIX, quando de sua profissionalização na Alemanha. Desde então, "aqueles que preparam outros historiadores (...) são eles próprios membros do corpo acadêmico", tornando-se a aspiração profissional dos jovens ingressantes. Para o autor, "o desafio não é libertar alguém dessa aspiração, mas, antes, libertá-lo de uma resposta automática a essa aspiração”. Nesse sentido, ele também destaca que a quanti- dade de vagas para docentes nas universidades não comporta o número de doutores em História: em outras palavras, "as carreiras acadêmicas não podem e não irão absorver todos os historiadores disponíveis" (p. 64). De modo semelhante, temos assistido no Brasil ao expressivo aumento do número de recém-titulados em decorrência da expansão dos programas de pós-graduação em História: temos atualmente 69 programas, sendo que 37 contemplam o doutorado. ${ }^{1}$

Dessa forma, o terceiro capítulo ( $A$ Multitude of Opportunites: Sites, Forms, Kin$d s$, and Users of History) nos é interessante à medida que enfoca e problematiza as possibilidades de atuação do historiador fora do meio acadêmico, bem como os públicos que se interessam por história. Banner Jr. assinala o papel que um vasto grupo formado por editores, designers e especialistas em marketing e venda desempenha na circulação do conhecimento histórico, assim como os curadores em mostras de temática histórica, que lidam diretamente com o grande público.

Para além de editoras e museus (para citar apenas dois exemplos), o autor destaca a possibilidade de um historiador atuar de modo independente. Ele aponta para o pequeno número de historiadores que foram bem-sucedidos como escritores de livros de história, em que pesem os desafios enfrentados pela ausência de vínculo institucional. Novamente, se remontarmos ao nosso caso, percebemos uma diferença entre os Estados Unidos e o Brasil: contrariamente aos co-

\footnotetext{
${ }^{1}$ De acordo com a Relação de Cursos Recomendados e Reconhecidos pela Coordenação de Aperfeiçoamento de Pessoal de Nível Superior (Capes).
} 
legas de lá, nossos principais escritores de livros de história são, em sua maioria, jornalistas (como Laurentino Gomes, Eduardo Bueno e Leandro Narloch) sem formação acadêmica em História. Esse fenômeno, o da "narrativa jornalística da história", requer um debate mais aprofundado no meio acadêmico brasileiro, embora o pontapé inicial já tenha sido dado pelo historiador Rodrigo Bragio Bonaldo em dissertação defendida em 2010. ${ }^{2}$

É certo, porém, que existe uma relativa dificuldade em escrever para o grande público, pois essa habilidade requer um treinamento que o historiador, em geral, não tem (seja no Brasil, seja nos Estados Unidos). Banner Jr. percebe que os programas de pós-graduação, assim como a maioria dos departamentos, tendiam (até há pouco tempo) a priorizar o preparo convencional. Mesmo quando havia treinamento e prática formais para desenvolver um repertório mais diversificado de habilidades, "a ausência de incentivos e de reconhecimento para atingir círculos extra-acadêmicos continuava a inibir a disseminaçáo do treinamento na escrita para um público mais amplo" (p. 74).

Ainda assim, o autor reitera que o conhecimento produzido na academia não pode mais ter como único destinatário seus pares acadêmicos, mas deve também abarcar os "cidadãos bem informados", os "curiosos",

${ }^{2}$ BONALDO, Rodrigo Bragio. Presentismo e presentificação do passado: a narrativa jornalística da história na Coleção Terra Brasilis de Eduardo Bueno. Porto Alegre: UFRGS, 2010. 169 p. Dissertação (Mestrado em História) — Programa de Pós-Graduação em História, Instituto de Filosofia e Ciências Humanas, Universidade Federal do Rio Grande do Sul, Porto Alegre, 2010. os "aficionados" por determinados temas do passado, o "governo" e outras corporaçóes. Essa constatação não implica, contudo, desconsiderar a importância da academia na produção e legitimidade do conhecimento histórico.

Sem as monografias e os artigos de periódicos escritos por acadêmicos para acadêmicos, sem a especializaçáo e a confiança na obra de outros acadêmicos (que se tornaram visíveis pelo uso da tão ridicularizada nota de rodapé), o conhecimento histórico teria permanecido parte do mundo da especulação amadorística, e náo teria se tornado uma parte constitutiva da compreensão humana, baseada na evidência bem fundamentada, na interpretação sujeita à avaliação e à revisão, e nos acréscimos em aberto. Ademais, sem a erudição monográfica, os popularizadores da história - escritores não acadêmicos e cineastas especialmente - não teriam tido à sua disposição o conhecimento que empresta à sua obra a credibilidade que ela possui. (p. 72)

Apesar deste reconhecimento no que concerne ao papel desempenhado pela academia, Banner Jr. insiste nos círculos extra-acadêmicos (em especial, nos diferentes públicos que reivindicam o acesso ao conhecimento histórico), bem como na capacidade de adaptaçáo e de inovação do historiador em atender a essas demandas. Indo além, o autor também critica, no quinto capítulo, a tímida atuação dos departamentos de histó- 
ria no preparo de professores para a própria academia, uma vez que a formação recai sobre a prática da pesquisa, e não sobre a prática do ensino.

A partir do quinto capítulo (History outside the Academy), Banner Jr. desdobra a noção de história pública, destacando que a crise de emprego na década de 1970 entre os novos doutores impulsionou o desenvolvimento da história pública nos Estados Unidos. Nesse contexto, ele explica que "o desejo de permanecer historiador profissional por parte daqueles que se frustraram na procura de uma colocação acadêmica explica muito do crescimento da história pública” (p. 135). Ao mesmo tempo, o autor acrescenta que o aumento da demanda por conhecimento histórico criou não apenas novas práticas e oportunidades para os historiadores, mas também renovou o modo de conceber o significado desse conhecimento. No entanto, ele percebe que a história pública não goza de grande estima no que se refere ao seu nível de autoridade intelectual. Diferentemente da história acadêmica, as práticas históricas públicas são ainda recentes, e sua baixa estima incide no (não) recrutamento das mentes jovens mais brilhantes.

Assim, Banner Jr. ressalta duas diferenças primordiais entre a história acadêmica e a história pública a partir da caracterização desta última. A primeira diferença refere-se à "utilidade direta, mais que a aplicabilidade difusa, do conhecimento histórico aos assuntos humanos" (p. 144). A "utilidade direta" da história pública consiste na resposta aos interesses específicos do público não acadêmico sobre questóes do passado, afetando sua compreensão do mundo. Já a segunda diferença relaciona-se, em certa medida, à primeira apontada. A história acadêmica procura, principalmente, avançar o conhecimento humano e integrar o conhecimento novo ao mais antigo em benefício, em sua maioria, dos acadêmicos e dos estudantes" (p. 144). Por seu turno, a história pública procura avançar a compreensão sobre o passado entre o público náo acadêmico, fazendo com que a reflexão histórica aconteça fora da sala de aula ao encorajar as pessoas a interpretarem esse passado. Ademais, os materiais e os meios de pesquisa da história pública não se limitam aos livros e aos manuscritos, mas englobam, sobretudo, a comunidade — "seus prédios, seus bairros, seus produtos industriais e outras dimensões de seu passado" (p. 148).

É verdade que o autor torna-se repetitivo em certos pontos do livro em decorrência, em parte, de seu próprio didatismo. Ao mesmo tempo, ele evidencia uma realidade do historiador nos Estados Unidos que suscita questionamentos interessantes também à nossa realidade. Ao apenas tangenciar questóes epistemológicas da disciplina, ele enfoca, principalmente, os profissionais que fazem uso dela e que contribuem para a produção e a disseminação do conhecimento histórico dentro da universidade ou fora dela. Desse modo, os públicos da história também entram em pauta no livro, porque eles não são apenas os destinatários do conhecimento produzido, mas são, especialmente, aqueles que demandam e interpretam esse tipo de conhecimento.

Em suma, o livro pode ser o ponto de partida para que o historiador brasileiro re- 
flita sobre diferenças e semelhanças relativas ao exercício de nossa profissão nos dois países. O intento comparativo pode, entâo, desdobrar-se em uma abordagem mais ampla, que preze pela articulação de novos espaços de atuação profissional com a redefiniçấo de nosso papel na sociedade. Logo, ser historiador no Brasil nos dias de hoje requer o aprofundamento da reflexão acerca do futuro de nosso ofício. 